Background Some crashes, particularly single vehicle crashes, may result from intentional self-harm behaviour but research on this topic is limited. Self-harm is the deliberate injuring of oneself and includes actions such as cutting, attempted hanging and poisoning. This study aimed to assess the risk that intentional self-harm poses for prospective motor vehicle crashes among novice drivers.

Methods Questionnaire responses from 20822 newly licensed drivers aged 17 to 24 were prospectively linked to licensing and police-reported crash data. The mean follow-up was 2 years. Multivariable Poisson regression models were used to investigate the role of recent self-harm on the risk of crash, taking into account potential confounders including driving exposure, duration of sleep, remoteness of residence, socio-economic status, psychological symptoms and substance abuse.

Results A total of 871 drivers reported engaging in self-harm in the year before the survey. Self-harm was more common among youth who were women, Australian-born, living in rural areas, driving more per week, sleeping less and using drugs and alcohol. Young people who reported engaging in self-harm behaviour were at significantly increased risk of crash (RR 1.42; 95\% CI 1.15 to 1.76 unadjusted; RR 1.37; 95\% CI 1.09 to 1.72 adjusted).

Interpretation This first and largest ever study of the relationship between self-harm and crash in young drivers found self-harm to be a predictor of subsequent motor vehicle crash, with most crashes involving multiple vehicles.

\section{SELF-HARM AND RISK OF MOTOR VEHICLE CRASHES IN YOUTH: THE DRIVE PROSPECTIVE COHORT STUDY}

A L C Martiniuk*, R 0 Ivers, N Glozier, G C Patton, L T Lam, S Boufous, T Senserrick, A Williamson, M Stevenson, R Norton Correspondence: The George Institute for International Health, M201 Missenden Rd, Camperdown -Sydney, NSW 2050, Australia 